\title{
An Empirical Test of the Cross-group Network Externality of Two-sided Market
}

\author{
Taking the Bankcard Industry as Example \\ Minghong Zhang , Zhenbo Zhang , Lingyi Hu \\ Department of Public Finance, School of Economics \\ Xiamen University \\ Xiamen, China \\ E-mail:yttl55666@163.com
}

\begin{abstract}
In order to inspect the existence and the intensity of the cross-group network externality of two-sided market, this article chooses the relevant data of bankcard industry from 1996 to 2010 and makes an empirical test with Granger test and sectional regression. The conclusion indicates that the bankcard industry has significant cross-group network externality in our country, which mainly reflects in the market after year 2002, and the intensity of the influence on each other between card-owners and merchants is similar. There are two points of innovations in this article. One is defining the average-card expenditure and the average-POS sales as the utility of card owner and merchant respectively. The other is to compare the intensity of cross-group network externality in different periods.
\end{abstract}

Keywords-Two-sided market; Cross-group network externality; Bankcard industry

\section{INTRODUCTION}

Two-sided market is a hot issue of economics of network in recent years. According to Armstrong(2006), two-sided market can be defined as a market in which users in two ends need to trade via an intermediate platform and the earning of one side is decided by the number of the other side.[1] We can find two-sided market has a special network externality called cross-group network externality. Network externality is a characteristic as the utility a user derives from consumption increases with the number other users consuming the same products or its complementary products. The essence of network externality(or network effect, this article refers specifically network externality) is scale economy of demand sides which exists in the synergy value of products. Katz and Shapiro(1985) firstly divided network externality as direct network externality and indirect network externality.[2] Cross-group network externality means the utility of users in one side increase as the number of the users in the other side gets larger in an intermediate platform[3]. It indicates that cross-group network externality belongs to the indirect network externality. The relationship of users in two sides is actually complementary and cross-group network externality is specially owned by two-sided market. Accordingly, self-owned network externality means utility of uses in one side increases as the scale of the network in this side gets larger. This article mainly focuses on the analysis of cross-group network externality.
This article takes the bankcard industry as the example to do an empirical test on the existence and intensity of crossgroup network externality. The cross-group network externality of bankcard industry indicates that the utility of card-owner improves as the number of users of merchants increases. Meanwhile, the utility of merchants gets more as the number of card-owner increases. We will analyze the topic in two parts.

Firstly, we inspect whether there exists obvious crossgroup network externality in our nation's bankcard industry. The resources of researches in empirical tests of network externality are abundant. But research findings of crossgroup network externality in two-sided market especially bankcard industry are few. Pinliang Luo and others(2010) have shown our bankcard industry does have weak crossgroup network externality which means the change of number of merchants leads to the change in consumer numbers. However, the contrary is of mistake. They also have got the result that the coefficient of cross-group network externality in the relationship between consumer and merchant is 0.876.[4] Lianying $\mathrm{Fu}(2011)$ adopted the same index to describe cross-group network externality and self-owned network externality of bankcard industry in the meantime via Attachment Curves Model. He got the conclusion that the bankcard industry in our country has weak cross-group network externality. [5] Therefore, it's necessary to find suitable indexes to measure the utility of card-owners and merchants in bilateral transaction and we have some try to complete this research.

secondly, this article inspects the difference of intensity of cross-group network externality in bankcard industry before and after year 2002 by applying sectional regression. The first domestic bankcard was released in 1985 and the Golden Card Project was carried out in 1997. China's national Yinlian was founded in 2002 and since when the bankcard industry was continuously developing. China's national Yinlian has provided a high-efficient platform for the improvement of whole industry. This article regards the year 2002 as the boundary and gets relevant result through testing the intensity of cross-group network externality in different periods. There are still no similar study in our country at present.

\section{EMPIRICAL APPROACH AND COLLECTION OF DATA}

First of all, we adopt Granger test to inspect the crossgroup network externality in China's bankcard industry. 
According to the analysis above, if taking no regard of the structure of bank price, utility of card-owners can be equal with the expenditure. Likewise, the utility merchants will achieve is equal with the consumption sum. As a consequence, we define the average-card expenditure and the average-POS sales as the utility of card owner and that of merchant in each year respectively. This definition has eliminated the influence of self-owned network externality and meanwhile has made the index more realistic as the utilities of two sides are acquired only in mutual trade. Due to the phenomenon of multi-homing, the number of cards and POS machines to a certain extent cann't represent the number of card-owners and merchants. But in accordance with the indexes above, we have properly defined the variables.

We use the method of OLS to estimate the cross-group network externality of bankcard industry before and after 2002.

Data including the number of domestic bankcard(N1), the number of POS machine(N2), average-card expenditure(U1) and average-POS sales(U2) are collected from China Financial Yearbook(1997-2011) and China Payment System Development Report(2006-2011).

\section{Test Of The EXISTENCE Of Cross-Group NETWORK EXTERNALITY}

\section{A. Stationary Test}

Stationarity is the precondition to do time series analysis. In this article, we use the method of ADF to do stationary test for the number of domestic bankcard(N1), the number of POS machine(N2), average-card expenditure(U1) and average-POS sales(U2). The results are shown in Table I .

We can conclude from Table II that he number of domestic bankcard(N1), average-card expenditure(U1) and average-POS sales(U2) are first-order difference stationary data and the number of POS machine(N2) is second-order difference stationary series.

\section{B. Granger Test}

To inspect the existence of cross-group network externality in two-sided market, this article adopts Granger test to examine whether the number of cards(N1) has function of facilitatory to average-POS sales(U2) and the number of POS machine(N2) has the same function to average-card expenditure(U1). As Granger test is quite sensitive to lag orders, we choose one order to three orders to do the test and the results are shown in Table II and Table III.

TABle II GRAnger Test Result OF N1 And U2

\begin{tabular}{|c|c|c|c|}
\hline NULL HYPOTHESIS & $\begin{array}{c}\text { LAG } \\
\text { ORDER }\end{array}$ & $\begin{array}{c}\text { P } \\
\text {-VALUE }\end{array}$ & $\begin{array}{c}\text { TEST } \\
\text { RESULT }\end{array}$ \\
\hline U2 does not Granger Cause N1 & \multirow{2}{*}{1} & 0.1282 & Accept \\
\cline { 1 - 2 } N1 does not Granger Cause U2 & & 0.0418 & Refuse \\
\hline U2 does not Granger Cause N1 & \multirow{2}{*}{2} & 0.1178 & Accept \\
\cline { 1 - 2 } N1 does not Granger Cause U2 & & 0.0927 & Refuse \\
\hline U2 does not Granger Cause N1 & \multirow{2}{*}{3} & 0.0925 & Refuse \\
\cline { 1 - 1 } N1 does not Granger Cause U2 & & 0.1008 & Accept \\
\hline
\end{tabular}

Table III GRanger Test Result Of N2 And U1

\begin{tabular}{|c|c|c|c|}
\hline NULL HYPOTHESIS & $\begin{array}{c}\text { LAG } \\
\text { ORDER }\end{array}$ & $\begin{array}{c}\text { P - } \\
\text { VALUE }\end{array}$ & $\begin{array}{c}\text { TEST } \\
\text { RESULT }\end{array}$ \\
\cline { 1 - 2 } U1 does not Granger Cause N2 & \multirow{2}{*}{1} & 0.1001 & Accept \\
\cline { 1 - 3 } N2 does not Granger Cause U1 & \multirow{2}{*}{2} & 0.0084 & Refuse \\
\hline U1 does not Granger Cause N2 & & 0.2593 & Accept \\
\cline { 1 - 3 } N2 does not Granger Cause U1 & \multirow{2}{*}{3} & 0.0006 & Refuse \\
\cline { 1 - 3 } U1 does not Granger Cause N2 & & 0.1118 & Refuse \\
\hline N2 does not Granger Cause U1 & & & Accept \\
\hline
\end{tabular}

We can conclude from Table II that under the confidence level of $10 \%$, the number of bankcard(N1) acts a significant guide to average-POS sales(U2), which indicates cardowners have cross-group network externality to merchants. Similarly, according to Table III the number of POS machine(N2) has the same function to average-card expenditure(U1), which indicates merchants also have crossgroup network externality to card-owners. The analysis above shows there exist clear cross-group network externality in nation's bankcard industry.

\section{TEst Of InTENSITy Of Cross-Group Network EXTERNALITY}

We use OLS to estimate the intensity of cross-group network externality in bankcard industry of China and compare its difference before and after 2002. Average-card expenditure and average-POS sales are both influenced by the number of bankcards and POS machines respectively, so the model will contain N1 and N2 together. Result is shown in Table IV.

As shown in Table IV, model 1, model 3, model 4 and model 6 have relatively high adjusted R-square and the independent variables have passed the T-test, which means those regress functions have favorable fitting degree and the results are evident. However, model 2 and model 5 have relatively low adjusted R-square and the fitting degree is poorer. Meanwhile, the coefficients of independent variables of model 2 are not evident. At the same time, we can find that bankcards dos not affect the utility of card-owners and so does the number of POS machines to the utility of merchants.

From the comparisons between the regression results of model 2 and model 3, model 5 and model 6,there is an significant difference of cross-group network externality in China's bankcard industry before and after 2002. From 1996 to 2001 ,bankcard industry has been starting and developed in a low speed although the Golden Card Project had already completed. Under this condition the market did not show the cross-group network externality it should have. However, after the year 2002, bankcard industry has come the the age of Yinlian and the strategy of universa-usage began to be carried out. Consequently the market mechanism was gradually perfected which shows obvious cross-group network externality.

Secondly we discover from model 1 that when the number of POS machines increases by ten thousand, average-bankcard expenditure will increase by 13.4 yuan correspondly, which indicates that improving in number of POS machines will bring an increase of bankcard utility. Similarly, model 4 shows that sales of each POS machine 
will increase by 14.1 yuan when adding ten thousand POS machines, which means the increase of number of bankcards will bring about relevant raise in utility of POS machines.

\section{CONCLUSION}

This article mainly focuses on testing the cross-group network externality of two-sided market based on data of China's bankcard industry from 1996 to 2010. According to the definition of cross-group network externality, we choose average-bankcard expenditure and average-POS sales to measure the utility of card-owners and merchants respectively. By Granger test we can ensure whether crossgroup network externality exist in bankcard industry. Furthermore, by comparing the difference in intensity of cross-group network externality before and after 2002, here are the conclusions:(1)China's bankcard industry has obvious cross-group network externality which mainly reflects after year 2002.(2)The intensity of the effect that card-owners and merchants have with each other are similar.

\section{REFERENCES}

[1] Armstrong, M. "Competition in two-sided markets". The RAND Journal of Economics, Vol.37,No.3, pp. 668-691,2006

[2] Katz M L, Shapiro C. "Network Externalities, Competition, and Compatibility”. The American Economic Review. Vol 75, No.3, pp. 424-440,1985

[3] Roson,R, “Two -Sided Market : A Tentative Survey”, Review of Network Economics,No.2, pp. 142- 160 ,2006

[4] Pinliang Luo, ect al. “Two-Sidedness Test of China’s Payment Card Market and Its Policy Implications”. Industrial Economics Research, No.2,pp.64-72,2010

[5] Lianying Fu. Study on Weak Two-sidedness of China's Payment Card Industry an its strategy of price structure. Ph.D Paper. ShangHai: FuDan University,2011

TABLE I ADF TEST OF UNIT RoOT

\begin{tabular}{|c|c|c|c|c|c|c|}
\hline \multirow{2}{*}{ Data Style } & \multicolumn{4}{|c|}{ P- Value } & Confidence & \multirow{2}{*}{ Test Result } \\
\cline { 2 - 4 } & Level & U1 & N2 & U2 & Accept \\
\hline Original data & 0.9999 & 1.0000 & 0.9967 & 0.6806 & \multirow{2}{*}{$10 \%$} & $\begin{array}{c}\text { N2 Accept } \\
\text { others Refuse }\end{array}$ \\
\hline first-order difference & 0.0664 & 0.9867 & 0.0064 & 0.0501 & \multirow{2}{*}{$10 \%$} & Refuse \\
\hline second-order difference & - & 0.0276 & - & - & & \\
\end{tabular}

TABLE IV REgRESSION RESUlt

\begin{tabular}{|c|c|c|c|c|c|c|}
\hline Model & Period & $\begin{array}{c}\text { Dependent } \\
\text { Variables }\end{array}$ & Constant & $\mathbf{N}_{1}$ & $\mathbf{N}_{2}$ & $\overline{R^{2}}$ \\
\hline Model 1 & $1996-2010$ & $U_{1 t}$ & $\begin{array}{l}403.5919 * * \\
(2.263638)\end{array}$ & $\begin{array}{c}-0.002133 \\
(-0.455088)\end{array}$ & $\begin{array}{c}13.43289 * * * \\
(3.590201)\end{array}$ & 0.880904 \\
\hline Model 2 & 1996-2001 & $U_{1 t}$ & $\begin{array}{c}615.9700 \\
(0.486540)\end{array}$ & $\begin{array}{c}-0.038220 \\
(-0.499854)\end{array}$ & $\begin{array}{c}35.39233 \\
(0.288598)\end{array}$ & -0.327711 \\
\hline Model 3 & $2002-2010$ & $U_{1 t}$ & $\begin{array}{c}-189.8501 \\
(1.823035)\end{array}$ & $\begin{array}{c}0.008145 \\
(1.405981)\end{array}$ & $\begin{array}{c}12.35644^{*} \\
(14.57368)\end{array}$ & 0.963536 \\
\hline Model 4 & $1996-2010$ & $U_{2 t}$ & $\begin{array}{l}35.41746^{* *} \\
(2.483356)\end{array}$ & $\begin{array}{c}0.001409 * * * \\
(3.758373)\end{array}$ & $\begin{array}{c}-0.197299 \\
(-0.659222)\end{array}$ & 0.879360 \\
\hline Model 5 & 1996-2001 & $U_{2 t}$ & $\begin{array}{l}112.2934 * * \\
(3.815547)\end{array}$ & $\begin{array}{c}0.000744 \\
(0.418548)\end{array}$ & $\begin{array}{c}-3.346788 \\
(-1.173967)\end{array}$ & 0.52054 \\
\hline Model 6 & $2002-2010$ & $U_{2 t}$ & $\begin{array}{c}-17.18536 \\
(-0.408488)\end{array}$ & $\begin{array}{l}0.002329 * * \\
(3.214508)\end{array}$ & $\begin{array}{c}-0.743925 \\
(-1.624573)\end{array}$ & 0.876942 \\
\hline
\end{tabular}

a: ***, **, * represent the results are significant under the confidence level of $1 \%, 5 \%$ and $10 \%$ respectively.

b:T Value in bracket 